\title{
Igualdad tributaria: reconstrucción racional de la jurisprudencia constitucional española
}

\author{
Patricia Toledo Zúñiga*
}

\begin{abstract}
RESUMEN
En este trabajo se discute respecto de la concreción del principio de igualdad tributaria. Su propósito es ser una contribución académica para la consolidación de la dogmática jurídica del principio de igualdad en materia tributaria. Específicamente, se analizan diferentes criterios que permitan establecer cuándo una desigualdad de trato en materia tributaria puede ser considerada arbitraria y, por tanto, una vulneración de este principio.

Para lograr este propósito se analiza el Derecho Comparado; específicamente, la jurisprudencia del Tribunal Constitucional español. El resultado de este trabajo se presenta elaborando una reconstrucción racional de estas sentencias, utilizando el modelo lógico de los sistemas normativos de Alchourrón y Bulygin.

Principios tributarios - igualdad en materia tributaria - Tribunal Constitucional español
\end{abstract}

\section{Tax Equity: A Rational Reconstruction \\ of Spanish Constitutional Jurisprudence}

\begin{abstract}
In this work I will discuss about the concretion of the principle of tax equity. Its purpose is being an academic contribution in order to consolidate the legal doctrine of tax equity. Specifically, I will analyze different conceptions of inequality and its treatment in tax matters; also, I will explore cases of violations of this principle.

To achieve the purpose, I analyze Comparative Law; specifically, jurisprudence of the Spanish Constitutional Court. The conclusions are consequences of a rational reconstruction of those decisions by using the logic model of normative systems of Alchourrón y Bulygin.
\end{abstract}

Tax principles - tax Equity - spanish Constitutional Court

* Licenciada en Ciencias Jurídicas y Sociales, Universidad Católica de Temuco. Doctora en Derecho, Universitat Pompeu Fabra, España. Profesora de Derecho Tributario, Universidad Católica de Temuco. Correo electrónico: ptoledo@uct.cl.

Artículo recibido el 30.8.2016 y aceptado para su publicación en esta número el 5.1.2018. 


\section{INTRODUCCIÓN}

$\mathrm{L}$ os ordenamientos jurídicos frecuentemente contienen normas constitucionales que positivizan el deber de contribuir al sostenimiento de los gastos públicos sujetándolo al cumplimiento de determinados criterios de distribución de la carga tributaria, que suelen denominarse principios constitucionales de Derecho tributario.

En este sentido, el artículo 19 N 20 de la Constitución Política de la República de Chile ${ }^{1}$ establece el principio de igualdad en materia tributaria ${ }^{2}$.

Los principios constitucionales de Derecho tributario constituyen garantías de los contribuyentes; sirven de justificación para restringir la potestad tributaria del Estado en la creación de leyes tributarias y en la dictación de nuevas sentencias. Sin embargo, la aplicación de un principio requiere -por su carácter de norma jurídica estructuralmente indeterminada- del trabajo de la doctrina y de la jurisprudencia para concretizar su contenido.

La dogmática jurídica acerca de los principios constitucionales de la tributación en Chile se encuentra en plena construcción. El objetivo de este trabajo es aportar en esta tarea avanzando en la concreción del principio de igualdad en materia tributaria; específicamente, se busca identificar criterios que permitan establecer cuándo una desigualdad de trato en materia tributaria puede ser considerada arbitraria y, por tanto, una vulneración de dicho principio.

Para lograr el objetivo planteado se ha optado por recurrir al Derecho comparado; específicamente se analizan los criterios de la jurisprudencia constitucional española.

Se ha optado por el Derecho español atendiendo a que la Constitución Española ${ }^{3}$, vigente desde 1978, contiene una disposición similar a la del art. 19 No 20 de la CPR de 1980, en la que se establece expresamente el principio de igualdad en materia tributaria como criterio de distribución de la carga del sostenimiento de los gastos públicos; se trata del art. 31.1 de la $\mathrm{CE}^{4}$. Se prefirió la jurisprudencia española atendiendo al continuo desarrollo del contenido del principio de igualdad en materia tributaria en ese país; se ha escogido la jurisprudencia del Tribunal Constitucional español porque en tal ordenamiento jurídico es el máximo intérprete de la $\mathrm{CE}^{5}$.

En la identificación de los criterios de la jurisprudencia constitucional española se busca realizar un cuidadoso trabajo descriptivo. Con todo, no pretende ser solo una

${ }^{1}$ En adelante CPR.

${ }^{2}$ El art. $19 \mathrm{~N}^{\circ} 20$ inciso $1^{\circ}$ de la CPR expresa: "La Constitución asegura a todas las personas: $20^{\circ}$. $\mathbf{L a}$ igual repartición de los tributos en proporción a las rentas o en la progresión o forma que fije la ley, y la igual repartición de las demás cargas públicas”. El destacado es mío.

${ }^{3}$ En adelante CE.

${ }^{4}$ El art. 31.1 de la CE expresa: “Todos contribuirán al sostenimiento de los gastos públicos de acuerdo con su capacidad económica mediante un sistema tributario justo inspirado en los principios de igualdad y progresividad que, en ningún caso, tendrá alcance confiscatorio”. El destacado es mío.

${ }^{5}$ El art. 1.1. de la Ley Orgánica 2/1979, de 3 de octubre, del Tribunal Constitucional dispone: "El Tribunal Constitucional, como intérprete supremo de la Constitución, es independiente de los demás órganos constitucionales y está sometido solo a la Constitución y a la presente Ley Orgánica”. El destacado es mío. 
mera recopilación de sentencias del Tribunal Constitucional español ${ }^{6}$ referentes al principio de igualdad en materia tributaria, sino que se intenta innovar presentando una reconstrucción racional de estas decisiones recurriendo a un modelo que hace uso de las herramientas que nos entrega la Teoría General del Derecho; en específico, el modelo de análisis lógico de sistemas normativos desarrollado por Alchourrón y Bulygin 7 -y que ha sido utilizado por autores como Moreso ${ }^{8}$ y MENDONCA ${ }^{9}-$ por su claridad en la sistematización de jurisprudencia.

Este trabajo se realiza con la convicción de que los resultados obtenidos tendrán valor no solo como mera sistematización de acontecimientos pasados en el ordenamiento jurídico español, sino como criterios para resolver casos futuros del ordenamiento jurídico chileno.

\section{ANÁLISIS DE LA JURISPRUDENCIA CONSTITUCIONAL}

Como se mencionó, para la sistematización de la jurisprudencia del Tribunal Constitucional español se recurrirá al modelo de análisis lógico de sistemas normativos desarrollados por Alchourrón y Bulygin en su obra Normative Systems.

El problema normativo que se intenta responder es: ¿Cuándo una desigualdad de trato en materia tributaria puede ser considerada arbitraria y, por tanto, una vulneración del principio de igualdad en materia tributaria?

Los pasos a seguir son tres: a) determinación del universo del discurso; b) determinación del ámbito fáctico de análisis; c) determinación del ámbito normativo de análisis.

\section{Determinación del universo del discurso (UD)}

En el modelo de Alchourrón y Bulygin el universo del discurso puede definirse como el "conjunto de todas las situaciones o estados de cosas posibles (casos individuales) caracterizados por una o varias propiedades, y que determinan los límites del sistema normativo analizado" 10 .

La determinación del universo del discurso implica selección en material jurídica relevante para responder al problema normativo planteado.

\footnotetext{
${ }^{6}$ En adelante se utilizará la abreviatura STC para referirse a una sentencia y la abreviatura SSTC para referirse a varias sentencias, en ambos casos se trata de resoluciones del Tribunal Constitucional español.

${ }^{7}$ Alchourrón, C., \& Bulygin, E. (1974. Trabajo original publicado en 1971). Introducción a la metodología de las ciencias jurídicas y sociales. (C. Alchourrón, \& E. Bulygin, Trads.) Buenos Aires: Astrea.

${ }^{8}$ Moreso, J. J. (2002). “Guastini sobre la ponderación”, en Isonomía, 17: págs. 227-245; Moreso, J. J. (2003). Conflictos entre principios constitucionales. En M. Carbonell (ed.), Neoconstitucionalismos (págs. 99121). Madrid: Trotta.

${ }^{9}$ Mendonca, D. (2003). Los derechos en juego. Conflicto y balance de derechos. Madrid: Tecnos.

${ }^{10}$ Martínez Zorrilla, D. (2010). Metodología y argumentación. Madrid: Marcial Pons, p. 287.
} 
El Tribunal Constitucional español ${ }^{11}$ se constituyó el 12 de julio de 1980; su primera resolución (auto) se dictó el 11 de agosto de 1980 y su primera sentencia se dictó el 26 de enero de 1981. La primera sentencia del Tribunal Constitucional se publicó en el Boletín Oficial del Estado No 47 el 24 de febrero de 1981; desde entonces y hasta el 31 de diciembre de 2014 se han publicado en el Boletín Oficial del Estado 7.669 sentencias.

El universo inicial de 7.669 SSTC fue necesario reducirlo hasta considerar solo aquellas SSTC donde se menciona el principio de igualdad en materia tributaria.

Para seleccionar el material jurídico relevante a efectos de este análisis, el universo inicial de 7.669 SSTC fue reducido en dos etapas sucesivas. En una primera etapa la búsqueda por medio de la utilización de bases de datos permitió reducir el número inicial a 43 SSTC; equivalente al 0,56 \% del universo inicial. En una segunda etapa la lectura e interpretación de estas 43 SSTC permitió reducirlas a 34 SSTC, lo que equivale al $0,44 \%$ del universo inicial. Por tanto, el universo del discurso quedó constituido por $34 \mathrm{SSTC}^{12}$.

\section{Determinación del ámbito fáctico de análisis}

En el modelo de Alchourrón y Bulygin el ámbito fáctico de análisis está compuesto por dos etapas: a) determinación de universo de propiedades; b) determinación del universo de casos.

\footnotetext{
${ }^{11}$ En adelante TC.
}

${ }^{12}$ Las 34 SSTC analizadas son las siguientes: 1) STC 27/1981, Pleno, de 20 de julio. FJs. $4^{\circ}$ y $5^{\circ} ; 2$ ) STC 209/1988, Pleno, de 10 de noviembre. FJs. $6^{\circ}$ a $11^{\circ}$; 3) STC 45/1989, Pleno, de 20 de febrero. FJs. $2^{\circ}$ y $4^{\circ}$ a $8^{\circ}$; 4) STC 76/1990, Pleno, de 26 de abril de 1990 . FJ $9^{\circ}$ A; 5) STC 150/1990, Pleno, de 4 de octubre. FJs. 7 y $9^{\circ}$; 6) STC 53/1993, Sala Segunda, de 15 de febrero. FJs. $1^{\circ}$ y $2^{\circ}$; 7) STC 54/1993, Sala Segunda, de 15 de febrero. FJs. $1^{\circ}$ y $2^{\circ}$; 8) STC 186/1993, Pleno, de 07 de junio de 1993 . FJ $4^{\circ}$ B; 9) STC 164/1995, Pleno, de 13 de noviembre de 1995 . FJ 7º 10) STC 214/1994, Pleno, de 14 de julio. FJs. $2^{\circ}$ y $4^{\circ}$ al $8^{\circ} ; 11$ ) STC 198/1995, Pleno, de 21 de diciembre de 1995. Ponente: Gabaldón López. BOE n 21 , de 24 de enero de 1996. [RTC 1995 \198]. FJ 3º, 12) STC 134/1996, Pleno, de 22 de julio. FJs. $5^{\circ}$ y $6^{\circ}$ al $9^{\circ} .13$ ) STC 72/1997, Pleno, de 10 de abril de 1997. FJ Único; 14) STC 80/1997, Sala Segunda, de 21 de abril de 1997. FJ Único; 15) STC 141/1997, Sala Segunda, de 15 de septiembre de 1997. FJ 3; 16) STC 159/1997, Pleno, de 2 de octubre. FJs. $3^{\circ}$ y $\left.4^{\circ} ; 17\right)$ STC 183/1997, Sala Primera, de 28 de octubre. FJs. $3^{\circ}$ y $4^{\circ} ; 18$ ) STC 55/1998, Sala Segunda, de 16 de marzo. FJs. $2^{\circ}$ y $3^{\circ}$; 19) STC 71/1998, Sala Segunda, de 30 de marzo. FJ. 5; 20) STC 137/1998, Sala Segunda, de 29 de junio de 1998. FJ 2; 21) STC 36/1999, Sala Primera, de 22 de marzo. FJ. $3^{\circ}$; 22) STC 84/1999, Sala Primera, de 10 de mayo. FJs. $3^{\circ}$ y $4^{\circ}$; 23) STC 200/1999, Sala Segunda, de 8 de noviembre. FJ. $3^{\circ}$; 24) STC 1/2001, Sala Segunda, de 15 de enero de 2001. FJ 3; 25) STC 111/2001, Sala Primera, de 7 de mayo. FJ. $7^{\circ}$; 26) STC 21/2002, Sala Segunda, de 28 de enero. FJs. $3^{\circ}$ y $4^{\circ}$; 27) STC 96/2002, Pleno, de 25 de abril. FJs. $6^{\circ}$ al $10^{\circ}$; 28) STC $193 / 2004$, Pleno, de 4 de noviembre. FJs. $3^{\circ}$ al $7^{\circ}$; 29) STC 255/2004, Pleno, de 23 de diciembre. FJs. $4^{\circ}$ al $6^{\circ}$; 30) STC 57/2005, Sala Segunda, de 14 de marzo. FJs. $3^{\circ}$ al $7^{\circ}$; 31) STC 33/2006, Sala Primera, de 13 de febrero de 2006. FJs. $3^{\circ}$ al $5^{\circ}$; 32) STC 54/2006, Sala Primera, de 27 de febrero de 2006. FJs. $5^{\circ}$ al $7^{\circ}$; 33) STC 295/2006, Pleno, de 11 de octubre. FJ. $8^{\circ}$; 34) STC 91/2007, Sala Segunda, de 7 de mayo. FJs. $3^{\circ}$ y $4^{\circ}$. 


\subsection{Determinación del universo de propiedades (UP)}

Habiendo fijado el universo del discurso en 34 SSTC a analizar, procede determinar el conjunto de propiedades consideradas relevantes por la jurisprudencia seleccionada. En otros términos, se debe analizar aquellas circunstancias cuya presencia o ausencia sirve de justificación para la resolución de las 34 SSTC determinadas.

Del análisis jurisprudencial mencionado es posible establecer tres reglas; una, de carácter procesal y las otras dos, de carácter sustantivo y complementario entre ellas.

a) El principio de igualdad en materia tributaria no se encuentra protegido por el recurso de amparo.

b) El principio de igualdad en materia tributaria no impide establecer tratamientos técnicos desiguales en el sostenimiento de las cargas fiscales.

c) El principio de igualdad en materia tributaria impone al legislador el deber de dispensar un mismo tratamiento a quienes se encuentran en situaciones jurídicas iguales, con prohibición de toda desigualdad arbitraria.

\subsubsection{El principio de igualdad en materia tributaria no se encuentra protegido por el recurso de amparo}

Al igual que el constituyente chileno, el constituyente español establece el principio de igualdad en varios de sus preceptos; así, entre otros, los arts. 1, 9, $14^{13}$ y 31, todos de la CE. Para efectos tributarios, el principio de igualdad está contenido en forma explícita en el art. 31.1 de la CE.

Determinar cuándo una eventual vulneración del principio de igualdad en materia tributaria está dentro del ámbito de protección del mencionado art. 14 de la CE y cuándo, dentro del ámbito de protección del art. 31.1 de la CE, cobra especial importancia en relación con el recurso de amparo. En efecto, mientras las vulneraciones de la garantía del art. 14 de la CE son recurribles en amparo; las vulneraciones del art. 31.1 de la CE carecen de tal protección.

Para determinar cuándo una desigualdad de trato ante la ley tributaria puede ser considerada una infracción del art. 14 de la CE -y, por tanto, susceptible de ser corregida mediante el proceso de amparo- el TC ha establecido como criterio atender al tipo de razones en que se basa la desigualdad. Así, si las razones son de carácter subjetivo, esto es, discriminaciones que pueda efectuar la ley tributaria en razón de circunstancias o cualidades que acompañan el carácter o condición del individuo, se entiende que pertenece al ámbito del art. 14 de la CE; en cambio, si se trata de razones de carácter objetivo, esto es, discriminaciones que pueda efectuar la ley tributaria en razón de circunstancias objetivas definidas en la ley como la capacidad económica de los contribuyentes,

${ }^{13} \mathrm{El}$ art. 14 de la CE expresa: "Los españoles son iguales ante la ley, sin que pueda prevalecer discriminación alguna por razón de nacimiento, raza, sexo, religión, opinión o cualquier otra condición o circunstancia personal o social”. Nótese que es una disposición de contenido similar a la del art. 19 No 2 de la CPR. 
se entiende que debe pertenecer exclusivamente al ámbito del art. 31.1 de la CE. Con todo, es posible destacar la labilidad del criterio mencionado.

A modo de ilustración, se cita la STC 159/1997, Pleno, de 2 de octubre, FJs. $3^{\circ}$ y $4^{\circ}$. Esta sentencia resuelve un Recurso de amparo interpuesto contra la sentencia del Tribunal Superior de Justicia de las Islas Baleares, de fecha 17 de diciembre de 1993, en relación con la aplicación de la tasa fiscal sobre los juegos de suerte, envite o azar creada por el art. 38.2.2 de la Ley 5/1990, de 29 de junio, sobre medidas en materia presupuestaria, financiera y tributaria.

Para los efectos de este trabajo, interesa la alegación de los recurrentes en cuanto a que la aplicación de la tasa fiscal respecto de los juegos de suerte, envite o azar supone una presión fiscal superior a la soportada por otras empresas dedicadas a modalidades distintas en el sector del juego. Por tanto, vulneraría el principio de igualdad ante la ley garantizado en el art. 14 de la CE.

El razonamiento del TC puede presentarse de la siguiente manera:

a) Primero, el TC aclara que la resolución impugnada aplica las reglas legales impositivas y que, indirectamente, lo que está en cuestionamiento es el régimen tributario de la tasa fiscal sobre los juegos de suerte, envite o azar.

b) Segundo, debido a que se alega vulneración del principio de igualdad ante la ley tributaria, el TC reitera la doctrina constitucional: la igualdad que se reclama en el art. 31 de la CE va íntimamente enlazada al concepto de capacidad económica y al principio de progresividad, por lo que no toda proclamación constitucional del principio de igualdad en materia tributaria es reconducible, sin más, a la efectuada por el art. 14 de la CE.

c) Tercero, el TC determina que el trato discriminatorio que se alega no atiende a las circunstancias personales o sociales a que se refiere el art. 14 de la CE; por lo contrario, se trataría de una diferenciación basada en elementos objetivos que es la contemplada por el art. 31.1 de la $\mathrm{CE}^{14}$.

${ }^{14}$ En esta sentencia el TC expresa por primera vez un criterio para distinguir entre los ámbitos de aplicación de los arts. 14 y 31.1 de la CE.

El TC declara: "Respecto al diferente contenido de la igualdad en los arts. 14 y 31.1 C.E. este Tribunal ha declarado que "la igualdad que se reclama en el art. 31 C.E. va íntimamente enlazada al concepto de capacidad económica y al principio de progresividad, por lo que no puede ser, a estos efectos, reconducida sin más, a los términos del art. 14 C.E." (STC 54/1993, fundamento jurídico $1^{\circ}$, con cita de la STC 27, fundamento jurídico $4^{\circ}$ ). Y en el mismo sentido, hemos precisado que la mención en el art. 31.1 C.E. del principio de igualdad conjuntamente con el de progresividad evidencia que el primero de ellos "no puede ser entendido en términos tales que impidan al legislador, al establecer el sistema fiscal que estima justo, introducir diferencias entre los contribuyentes, bien sea atendiendo a la cuantía de sus rentas, al origen de estas o cualesquiera condición social que considere relevante para atender al fin de la justicia”. De suerte que la vulneración del art. 14 C.E. por la Ley Tributaria solo se producirá, eventualmente, "cuando arbitrariamente se establezcan discriminaciones entre contribuyentes entre los cuales no media ninguna razón objetiva de diferenciación" (ATC 230/1984, fundamentos jurídicos $1^{\circ}$ y $2^{\circ}$ ). Lo que nos indica, en suma, la necesidad de distinguir las diferencias entre personas o grupos de personas por razones subjetivas, a las que se refiere el art. $14 \mathrm{y}$, de otro lado, las que contempla en el art. 31.1 C.E. en relación con el principio 
d) Cuarto, de conformidad con el art. 53.2 de la CE, la desigualdad de trato alegada no es susceptible de ser corregida por el cauce de proceso de amparo; sin perjuicio de que pueda serlo, en su caso, por el de otros procesos constitucionales como el recurso o la cuestión de inconstitucionalidad.

Por tanto, el TC deniega el amparo solicitado.

2.1.2. El principio de igualdad en materia tributaria no impide establecer tratamientos técnicos desiguales en el sostenimiento de las cargas fiscales

El TC se ha encargado de establecer en reiteradas ocasiones que el establecimiento del principio de igualdad en materia tributaria no prohíbe las desigualdades de trato.

En efecto, el principio de igualdad ante la ley (incluida la ley tributaria) impone al legislador el deber de dispensar un mismo tratamiento a quienes se encuentran en situaciones jurídicas iguales, con prohibición de toda distinción arbitraria; lo anterior no implica la prohibición de establecer tratamientos técnicos desiguales en el sostenimiento de las cargas tributarias.

A modo de ilustración, es factible citar la STC 27/1981, Pleno, de 20 de julio, FJs. $4^{\circ}$ y $5^{\circ}$. Esta sentencia resuelve un Recurso de inconstitucionalidad contra determinados artículos de la Ley 74/1980, de 29 de diciembre, de Presupuestos Generales del Estado para 1981.

Para los efectos de este trabajo, interesa la impugnación del art. 36 de la citada ley, que excluye de gravamen los incrementos de patrimonio obtenidos por enajenación de vivienda habitual cuando el total de la renta se reinvierta en la adquisición de una nueva vivienda habitual. Los recurrentes sostienen que la disposición impugnada no establece una exención del hecho imponible, sino solo una reducción del importe de los incrementos afectando a la base imponible; este hecho incidiría regresivamente en el impuesto y, por tanto, infringiría el art. 31.1 de la CE y, entre ellos, el principio de igualdad tributaria.

El TC declara que el principio de igualdad tributaria está íntimamente enlazado al concepto de capacidad económica y al principio de progresividad; por ello, no puede ser simplemente reconducido a los términos del art. 14 de la CE.

En cuanto a la posible infracción del principio de igualdad tributaria por la disposición impugnada, el TC razona de la siguiente manera:

a) Primero, el principio de igualdad tributaria prohíbe otorgar un tratamiento fiscal diverso entre los contribuyentes cuando concurren las mismas circunstancias en todos ellos.

de igualdad, basadas en razones objetivas atinentes a la renta o los ingresos de los sujetos". STC 159/1997, de 2 de octubre de 1997, FJ 3º. El destacado es mío. 
b) Segundo, la disposición impugnada implica otorgar un tratamiento legal diverso entre las plusvalías obtenidas a título oneroso y las que derivan de título lucrativo.

c) Tercero, el principio de igualdad tributaria no impide establecer tratamientos técnicos desiguales en el sostenimiento de las cargas fiscales.

En consecuencia, el TC rechaza que la disposición impugnada vulnere el principio de igualdad tributaria y, por tanto, desestima el recurso de inconstitucionalidad.

En un sentido similar -y también a modo de ilustración- es factible citar la STC 150/1990, Pleno, de 4 de octubre, FJ $7^{\circ}$. Esta sentencia resuelve un recurso de inconstitucionalidad contra la Ley de la Asamblea de la Comunidad Autónoma de Madrid 15/1984, de 19 de diciembre, del Fondo de Solidaridad Municipal de Madrid.

En los arts. 7 y 8 de ley madrileña citada se establece un recargo en el Impuesto sobre la Renta de las Personas Físicas ${ }^{15}$ consistente en un porcentaje único del $3 \%$ aplicable sobre la cuota líquida de dicho impuesto. El recargo es exigible a los mismos sujetos pasivos y en los mismos casos que en el IRPF, siempre que dichos sujetos pasivos tengan domicilio fiscal en cualquiera de los municipios integrantes de la Comunidad Autónoma de Madrid.

Los recurrentes sostienen que el recargo mencionado introduce una desigualdad en perjuicio de los residentes en la Comunidad Autónoma de Madrid carente de toda justificación objetiva y razonable.

El razonamiento del TC puede presentarse de la siguiente manera:

a) Primero, la Comunidad Autónoma de Madrid tiene potestad tributaria para establecer, mediante ley, recargos respecto de impuestos estatales ${ }^{16} \mathrm{y}$, en particular, de los que gravan la renta de las personas físicas con domicilio fiscal en su territorio.

b) Segundo, el principio de igualdad no impone que todas las Comunidades Autónomas tengan que ejercer sus competencias de una manera o con un contenido y unos resultados idénticos o semejantes. En efecto, la autonomía significaría precisamente la capacidad de cada nacionalidad o región para decidir cuándo y cómo ejercer sus propias competencias en el marco de la Constitución y de su Estatuto.

c) Tercero, como manifestación de su autonomía financiera, el ejercicio de competencia de la Comunidad Autónoma de Madrid para establecer recargos en los impuestos estatales no requiere una justificación explícita de la desigualdad tributaria que produce.

d) Cuarto, el TC aclara que la diversidad resultante por el establecimiento del recargo autonómico en el IRPF no quiebra la igualdad de posiciones jurídicas fundamentales de los ciudadanos en el cumplimiento de los deberes que les impone el

${ }^{15}$ En adelante: IRPF.

${ }^{16}$ El art. 157.1 de la CE expresa: "Los recursos de las Comunidades Autónomas estarán constituidos por: a) Impuestos cedidos total o parcialmente por el Estado; recargos sobre impuestos estatales y otras participaciones en los ingresos del Estado”. El destacado es mío. 
art. 31 de la CE; si así fuera, quedaría radicalmente eliminada la potestad de las Comunidades Autónomas para establecer recargos.

En consecuencia, el TC concluye que no se ha vulnerado el principio de igualdad y, por tanto, desestima el recurso de inconstitucionalidad.

2.1.3. El principio de igualdad en materia tributaria impone al legislador el deber de dispensar un mismo tratamiento a quienes se encuentran en situaciones jurídicas iguales, con prohibición de toda desigualdad arbitraria

El TC ha establecido que el principio de igualdad no prohíbe todas las desigualdades de trato, sino que impone al legislador el deber de dispensar un mismo tratamiento a quienes se encuentran en situaciones jurídicas iguales, con prohibición de toda desigualdad arbitraria. Por tanto, corresponde determinar cuáles son -a juicio del TC- las circunstancias que permiten establecer una desigualdad de trato en materia tributaria, sin que sea considerada arbitraria.

En este sentido, el TC ha declarado que el principio de igualdad en materia tributaria impone al legislador el deber de dispensar un mismo tratamiento a quienes se encuentran en situaciones jurídicas iguales, con prohibición de toda desigualdad que -desde el punto de vista de la finalidad de la norma cuestionada-carezca de justificación objetiva y razonable, o que resulte desproporcionada en relación con dicha finalidad.

El examen del cumplimiento de estas condiciones se ha denominado juicio de igualdad. Luego, ante una disparidad de trato cuestionada, "el juicio de igualdad" implica verificar lo siguiente:

a) Que los términos de comparación sean homologables o idóneos.

b) Que exista una finalidad que justifique el establecimiento de la desigualdad de trato.

c) Que la medida de desigualdad adoptada resulte proporcionada en relación con la finalidad perseguida.

d) Además, la doctrina constitucional reciente ha incorporado una nueva condición al juicio de igualdad que se ha denominado criterio de la normalidad.

\section{A. Que los términos de comparación sean homologables o idóneos}

El TC ha declarado que para apreciar una vulneración del principio de igualdad en materia tributaria es necesario que los términos de comparación que se aportan para fundamentar la desigualdad denunciada sean homogéneos.

Para ilustrar esta exigencia se cita la STC 76/1990, Pleno, de 26 de abril, FJ $9^{\circ}$ A. Esta sentencia resuelve un recurso de inconstitucionalidad y dos cuestiones de inconstitucionalidad acumulados, contra determinados preceptos de la Ley 10/1985 de modificación parcial de la LGT/1963. 
Para los efectos de este trabajo interesa la impugnación del art. 58.2 b) de la LGT/1963 que en su nueva redacción establece que el interés de demora será el interés legal del dinero vigente el día que comience el devengo de aquel, incrementado en $25 \%$, salvo que la Ley de Presupuestos Generales del Estado establezca uno diferente.

Los recurrentes sostienen que la disposición impugnada introduce un trato favorable a la Administración tributaria discriminando injustificadamente a los contribuyentes. Esto, porque cuando la Administración tributaria debe devolver ingresos que se hubieran realizado indebidamente, los contribuyentes solo tienen derecho al interés legal; en cambio, cuando el contribuyente se retrasa en el pago de las deudas fiscales, la Administración tributaria tiene derecho al interés legal incrementado en $25 \%$. A juicio de los recurrentes, la situación mencionada vulneraría el principio de igualdad establecido en el art. 14 en relación con el art. 31.1, ambos de la CE.

El razonamiento del TC puede presentarse de la siguiente manera:

a) Primero, el TC reitera la doctrina constitucional acerca del principio de igualdad resumiéndola en los siguientes términos: “a) no toda desigualdad de trato en la ley supone una infracción del art. 14 de la Constitución, sino que dicha infracción la produce solo aquella desigualdad que introduce una diferencia entre situaciones que pueden considerarse iguales y que carece de una justificación objetiva y razonable; b) el principio de igualdad exige que a iguales supuestos de hecho se apliquen iguales consecuencias jurídicas, debiendo considerarse iguales dos supuestos de hecho cuando la utilización o introducción de elementos diferenciadores sea arbitraria o carezca de fundamento racional; c) el principio de igualdad no prohíbe al legislador cualquier desigualdad de trato, sino solo aquellas desigualdades que resulten artificiosas, o injustificadas por no venir fundadas en criterios objetivos y suficientemente razonables de acuerdo con criterios o juicios de valor generalmente aceptados; d) por último, para que la diferenciación resulte constitucionalmente lícita no basta con que lo sea el fin que con ella se persigue, sino que es indispensable además que las consecuencias jurídicas que resultan de tal distinción sean adecuadas y proporcionadas a dicho fin, de manera que la relación entre la medida adoptada, el resultado que se produce y el fin pretendido por el legislador superen un juicio de proporcionalidad en sede constitucional, evitando resultados especialmente gravosos o desmedidos" 17 .

b) Segundo, el TC aplica el denominado juicio de igualdad a la diferenciación en cuestionamiento.

En cuanto a los términos de comparación, el TC determina que los términos de comparación presentados por los recurrentes no son homogéneos. El TC declara que la Administración tributaria se encuentra en una situación de superioridad en relación con los obligados tributarios. El fundamento de esta desigualdad de trato se encontraría en el art. 31.1 de

${ }^{17}$ STC 76/1990, Sala Pleno, de 26 de abril de 1990, FJ $9^{\circ}$ A. El destacado es mío. 
la CE que, al configurar el deber tributario como deber constitucional, está autorizando al legislador para que, dentro de un sistema tributario justo, adopte las medidas que sean eficaces y atribuya a la Administración las potestades necesarias para exigir y lograr el cumplimiento de las obligaciones tributarias por parte de los ciudadanos.

En cuanto a la finalidad perseguida, el TC declara que consiste en evitar el grave perjuicio que para la Hacienda supondría que grupos enteros de contribuyentes dejaran en masa de pagar sus cuotas tributarias, porque el costo del retraso les supusiera, de todos modos, un ahorro respecto del interés de mercado del dinero. Un riesgo de tal magnitud numérica y cuantitativa no sería asimilable a la situación que se produce cuando el contribuyente es acreedor frente a Hacienda. Por tanto, el TC concluye que la diferenciación normativa no es injustificada ni arbitraria.

En cuanto a la proporcionalidad de la medida adoptada en relación con la finalidad perseguida, el TC establece que el incremento del $25 \%$ sobre el interés legal, salvo que la Ley de Presupuestos Generales establezca uno diferente, resulta razonable considerando los tipos de interés existentes en el mercado financiero; en otros términos, el tipo de interés fijado no supone un sacrificio excesivo para el contribuyente moroso considerando los aplicables habitualmente en las relaciones entre particulares.

Por todo lo anterior, el TC concluye que la diferenciación normativa establecida por el art. 58.2 b) de la LGT/1963 en la redacción dada por la Ley 10/1985 es legítima y, por tanto, desestima el recurso de inconstitucionalidad y las dos cuestiones de inconstitucionalidad acumulados.

\section{B. Que exista una finalidad que justifique el establecimiento de la desigualdad de trato}

El TC ha declarado que "el principio de igualdad no prohíbe al legislador cualquier desigualdad de trato, sino solo aquellas desigualdades que resulten artificiosas, o injustificadas por no venir fundadas en criterios objetivos y suficientemente razonables de acuerdo con criterios o juicios de valor generalmente aceptados" 18 .

Para ilustrar esta exigencia se cita la STC 134/1996, Pleno, de 22 de julio, FJs. $6^{\circ}$ al $9^{\circ}$. Esta sentencia resuelve un recurso de inconstitucionalidad contra el art. 62 de la Ley 21/1993, de 29 de diciembre, de Presupuestos Generales del Estado para 1994, por la modificación introducida al art. 9.1 letras b) y c) de la Ley 18/1991, de 6 de junio, del IRPF.

Con la modificación impugnada: a) dejan de estar exentas del IRPF todas las pensiones por incapacidad permanente; b) se mantienen exentas del IRPF las pensiones por gran invalidez; c) tratándose de las pensiones de incapacidad permanente absoluta solo se mantienen exentas cuando son reconocidas por la Seguridad Social, pero no las causadas por los funcionarios públicos.

Para los efectos de este trabajo, interesa la alegación de los recurrentes en cuanto a que la modificación introducida vulnera el art. 31.1 de la CE, al otorgar un trato

${ }^{18}$ STC 76/1990, Sala Pleno, de 26 de abril de 1990, FJ $9^{\circ}$ A. 
discriminatorio ante la ley tributaria a las pensiones permanentes absolutas causadas por los funcionarios públicos en relación con las reconocidas por la Seguridad Social.

Para resolver si se configura la vulneración alegada, el TC aplica el denominado juicio de igualdad:

a) En cuanto a los términos de comparación aportados, el TC resuelve que son homogéneos. En efecto, tanto si son reconocidas por la Seguridad Social como causadas por los funcionarios públicos, en ambos casos, se trata de cantidades que percibe el trabajador cuando se encuentra afectado por una lesión física o psíquica que le impide desempeñar no solo las funciones que son propias de su oficio concreto, sino también las de cualquier otra profesión o empleo.

b) En cuanto a la justificación objetiva y razonable para la diferencia de trato mencionada, el TC aclara que en la Exposición de Motivos de la Ley 21/1993 el legislador no ha ofrecido justificación alguna.

Ahora bien, el TC reconoce que el legislador tributario goza de un ámbito de libertad de configuración; así, en cuanto a las pensiones o prestaciones por incapacidad el legislador puede optar por gravarlas, declararlas exentas o no sujetas al IRPF.

Con todo, en el ejercicio de su libertad de opción política el legislador tributario debe respetar los límites constitucionales; al declarar exentas las pensiones permanentes absolutas reconocidas por la Seguridad Social y no las causadas por los funcionarios públicos, careciendo de toda justificación razonable, el legislador tributario ha vulnerado el principio de igualdad tributaria.

Por tanto, el TC estima el recurso interpuesto y declara la inconstitucionalidad del art. 62 de la Ley 21/1993, de 29 de diciembre, de Presupuestos Generales del Estado para 1994 por infringir el art. 31.1 de la CE.

\section{Que la medida de desigualdad adoptada resulte proporcionada en relación con la finalidad perseguida}

El TC ha declarado que "para que la diferenciación resulte constitucionalmente lícita no basta con que lo sea el fin que con ella se persigue, sino que es indispensable además que las consecuencias jurídicas que resultan de tal distinción sean adecuadas y proporcionadas a dicho fin, de manera que la relación entre la medida adoptada, el resultado que se produce y el fin pretendido por el legislador superen un juicio de proporcionalidad en sede constitucional, evitando resultados especialmente gravosos o desmedidos"19.

Para ilustrar esta exigencia se cita la STC 209/1998, Pleno de 10 de noviembre, FJs. $6^{\circ}$ a $11^{\circ}$. Esta sentencia resuelve un recurso de amparo contra la sentencia de la Audiencia Territorial de Barcelona, de 19 de junio de 1985, concerniente a liquidación 
conjunta practicada al recurrente y a su cónyuge por haber contraído matrimonio el 27 de diciembre del año fiscal en litigio.

Para los efectos de este trabajo, interesa la alegación del recurrente de haber sido víctima de discriminación por razón de matrimonio, como consecuencia del régimen de acumulación de rentas familiares que le fue exigido por la resolución impugnada. Tal discriminación vulneraría el principio de igualdad establecido en los arts. 14 y 31.1 de la CE.

El razonamiento del TC puede presentarse de la siguiente manera:

a) Primero, la resolución impugnada aplica las reglas legales impositivas e, indirectamente, lo que está en cuestionamiento es el régimen tributario establecido en los arts. 4.2, 5.1 y conexos de la Ley 44/1978, de 8 de septiembre, del IRPF. Con todo, por tratarse de un recurso de amparo, estas reglas no pueden ser objeto directo del enjuiciamiento.

b) Segundo, el TC declara: a) la igualdad ha de valorarse teniendo en cuenta el régimen jurídico sustantivo del ámbito de relaciones en que se proyecte; b) en materia tributaria es el propio constituyente quien ha concretado y modulado el alcance del art. 14 de la CE en relación con el art. 31.1 de la CE; c) la igualdad ante la ley tributaria resulta indisociable de los otros principios (generalidad, capacidad, justicia y progresividad) enunciados en el art. 31.1 de la CE.

c) Tercero, el TC reitera la doctrina constitucional en relación con la igualdad en la ley: "para que las diferenciaciones normativas puedan considerarse no discriminatorias resulta indispensable que exista una justificación objetiva y razonable, de acuerdo con criterios y juicios de valor generalmente aceptados, cuya exigencia deba aplicarse en relación con la finalidad y efectos de la medida considerada, debiendo estar presente, por ello, una razonable relación de proporcionalidad entre los medios empleados y la finalidad perseguida" ${ }^{20}$.

Acto seguido, el TC aplica el denominado juicio de igualdad para comprobar que las diferenciaciones normativas en cuestión dan cumplimiento a las condiciones mencionadas.

d) En cuanto a los términos de comparación, el TC determina que se debe comparar la situación de los sujetos pasivos del IRPF cuyas rentas fueron acumuladas en una unidad familiar por razón de matrimonio en relación con los demás sujetos pasivos del IRPF. Por tanto, implica contrastar las situaciones respectivas de los contribuyentes según estén o no unidos en matrimonio. El TC concluye que, debido al carácter progresivo del IRPF, el diferente régimen jurídico que la ley dispone para la tributación de los sujetos pasivos según estén o no unidos por vínculo matrimonial tiende a provocar una mayor carga tributaria sobre el contribuyente casado respecto del que, con magnitud igual de renta, no lo está.

${ }^{20}$ STC 209/1988, Sala Pleno, de 10 de noviembre de 1988, FJ 6. El destacado es mío. 
e) En cuanto a la finalidad que persigue el legislador, el TC declara que el legislador ha presumido que la existencia del matrimonio y la confluencia de los rendimientos e incrementos de patrimonio de quienes lo forman producen en los cónyuges una capacidad distinta y superior a la que, de acuerdo con sus propias rentas, tendría cada uno de ellos, individualmente considerados. A causa de que el legislador habría establecido el régimen en atención a la capacidad económica de los sujetos pasivos del impuesto, el TC concluye que el establecimiento de la diferenciación no es arbitrario.

f) En cuanto a la proporcionalidad entre los medios empleados y la finalidad perseguida, el TC establece que si lo que implica el incremento de la capacidad económica de los sujetos pasivos del IRPF es la vida en común, entonces debe ser esta última circunstancia y no el hecho del matrimonio el supuesto de la norma reguladora del régimen en cuestión.

Luego, el régimen de discriminación de rentas genera un trato desigual entre los sujetos pasivos del IRPF que han contraído matrimonio en relación con los otros sujetos pasivos del IRPF que viven en común, en ausencia de vínculo matrimonial. En virtud de que tal trato desigual no aparece justificado en aras de otro valor constitucionalmente protegido, el TC concluye que se trata de un trato discriminatorio y, por tanto, resuelve otorgar el amparo solicitado por vulneración del principio de igualdad.

\section{Criterio de la normalidad}

La doctrina constitucional reciente ha incorporado una nueva condición al "juicio de igualdad" que se ha denominado "criterio de la normalidad".

El TC ha declarado que "para que las desigualdades generen una vulneración del derecho de igualdad no deben producirse en supuestos puntuales porque las leyes, en su pretensión de racionalidad, se proyectan en la normalidad de los casos, sin que baste la aparición de un supuesto no previsto, para determinar su inconstitucionalidad ${ }^{21}$.

Para ilustrar esta exigencia se cita la STC 193/2004, Pleno, de 4 de noviembre, FJs. $3^{\circ}$ al $7^{\circ}$. Esta sentencia resuelve una cuestión de inconstitucionalidad contra la redacción original del art. 90.2 de la Ley 39/1988, de 28 de diciembre, reguladora de las Haciendas Locales, en relación con el impuesto sobre actividades económicas. Se alega vulneración del art. 14 en relación con el art. 31.1, ambos de la CE.

La inconstitucionalidad que se imputa a la disposición impugnada consiste en otorgar un diferente trato fiscal entre quienes se dan de alta y quienes se dan de baja en el ejercicio de actividades económicas. En efecto, los primeros deben tributar de forma proporcional al número de trimestres en los que han ejercido la actividad; en cambio, los

${ }^{21}$ STC 193/2004, Sala Pleno, de 4 de noviembre de 2004, FJ $3^{\circ}$.

En sentido similar: STC 70/1991, de 8 de abril, FJ. 7; STC 308/1994, de 21 de noviembre, FJ. 5; STC 73/1996, de 30 de abril, FJ. 5; STC 289/2000, de 30 de noviembre, FJ. 6; STC 47/2001, de 15 de febrero, FJ. $7^{\circ}$; STC 21/2002, de 28 de enero, FJ. $4^{\circ}$. 
segundos, deben hacerlo por el año completo, con independencia de cuántos trimestres hayan ejercido la actividad efectivamente.

El razonamiento del TC puede presentarse de la siguiente manera:

a) Primero, el TC reitera la doctrina constitucional respecto del principio de igualdad ante o en la ley declarando que "impone al legislador el deber de dispensar un mismo tratamiento a quienes se encuentran en situaciones jurídicas iguales, con prohibición de toda desigualdad que, desde el punto de vista de la finalidad de la norma cuestionada, carezca de justificación objetiva y razonable, y resulte desproporcionada en relación con dicha justificación" 22 .

Asimismo, el TC expresa: "para que las desigualdades generen una vulneración del derecho a la igualdad no deben producirse en supuestos puntuales porque las leyes, en su pretensión de racionalidad, se proyectan sobre la normalidad de los casos, sin que baste la aparición de un supuesto no previsto para determinar su inconstitucionalidad" 23 .

b) Segundo, se alega un trato desigual ante la ley tributaria. Esta precisión es relevante porque la igualdad ha de valorarse teniendo en cuenta el régimen jurídico sustantivo del ámbito de relaciones en que se proyecta. "En la materia tributaria es la propia Constitución la que ha concretado y modulado el alcance de su art. 14 en un precepto, el art. 31.1, cuyas determinaciones no pueden dejar de ser tenidas aquí en cuenta, pues la igualdad ante la ley tributaria resulta indisociable de los principios de generalidad, capacidad, justicia y progresividad, que se enuncian en el último precepto constitucional citado" 24 .

c) Tercero, el TC aplica el denominado juicio de igualdad:

En cuanto a los términos de comparación ofrecidos, el TC establece que son homologables. En efecto, ambas situaciones son expresivas de la misma manifestación de riqueza potencial: el beneficio medio presunto que la norma atribuye a la actividad gravada durante un período de tiempo definido.

En cuanto a la justificación de la mencionada disparidad de trato, el TC establece: que no se ha ofrecido justificación alguna por el Abogado del Estado, que no se expresa en la exposición de motivos de la ley en cuestionamiento, que no puede hallarse en los debates parlamentarios y tampoco en posibles dificultades técnicas. Por tanto, el TC concluye que la disparidad de trato carece de justificación.

El TC declara que la desigualdad de trato cuestionada no tiene lugar en supuestos puntuales previstos en la norma, sino en la generalidad de los casos. En efecto, la disposición impugnada establece, para los períodos temporales inferiores al año natural derivados de las bajas en el ejercicio de actividades económicas, un

\footnotetext{
${ }^{22}$ STC 193/2004, Sala Pleno, de 4 de noviembre de 2004, FJ $3^{\circ}$.

${ }^{23}$ STC 193/2004, Sala Pleno, de 4 de noviembre de 2004, FJ $3^{\circ}$. El destacado es mío.

${ }^{24}$ STC 193/2004, Sala Pleno, de 4 de noviembre de 2004, FJ $3^{\circ}$.
} 
régimen tributario más gravoso, en su conjunto, que para idénticos períodos temporales derivados de declaraciones de alta.

Establecida la inexistencia de una razón que justifique el trato diferente, el TC expresa que no procede realizar examen alguno en relación con la proporcionalidad de la medida.

En consecuencia, el TC estima la cuestión de inconstitucionalidad y, consecuentemente, declara la inconstitucionalidad y nulidad de la disposición impugnada.

\subsubsection{Universo de propiedades relevantes: UP}

Para continuar el análisis se partirá del supuesto de que existe una desigualdad de trato ante la ley tributaria y se establecerá cuándo tal desigualdad vulnera el principio de igualdad en materia tributaria.

Para tal efecto, el universo de propiedades relevantes (UP) está constituido por los siguientes cuatro elementos:

1) Que exista homogeneidad entre los términos de comparación tratados desigualmente ante la ley tributaria. A esta propiedad relevante se le asignará la letra $\mathrm{H}$.

2) Que exista una justificación objetiva y razonable que fundamente la desigualdad de trato ante la ley tributaria. A esta propiedad relevante se le asignará la letra J.

3) Que exista proporcionalidad entre los medios utilizados y la finalidad perseguida. A esta propiedad relevante se le asignará la letra P.

4) Que se trate de un caso normal que pudiese haber previsto un legislador racional. A esta propiedad relevante le asignaremos la letra CN.

En resumen:

$$
U P=\{H, J, P, C N\}
$$

2.2. Determinación del universo de casos: UC

Habiendo determinado el universo de propiedades relevantes, procede determinar el universo de casos.

Se entiende por universo de casos (UC) el conjunto de casos genéricos posibles del sistema normativo.

El número total de casos genéricos depende de la cantidad de elementos del UP y puede calcularse mediante la siguiente fórmula, donde n es el número de elementos del UP:

$$
\mathrm{UC}=2^{\mathrm{n}}
$$

Nuestro universo de propiedades relevantes (UP) está constituido por cuatro elementos: $\mathrm{H}, \mathrm{J}, \mathrm{P}, \mathrm{CN}$; luego, nuestro universo de casos (UC) está constituido por $2^{4}=$ 16 casos genéricos. 


\section{Determinación del ámbito normativo de análisis}

En el modelo de Alchourrón y Bulygin el ámbito normativo de análisis está compuesto por dos etapas: a) determinación de universo de acciones; b) determinación del universo de soluciones.

\subsection{Determinación del universo de acciones: UA}

Procede determinar el universo de acciones (UA). El universo de acciones se puede definir como "el conjunto de comportamientos deónticamente modalizados por el sistema normativo analizado" 25 .

Para nuestros efectos, limitaremos la extensión del universo de acciones (UA) a la siguiente acción: exigir contribuir al sostenimiento de los gastos públicos; le asignaremos las letras DC.

Con el fin de identificar que los resultados obtenidos están relacionados con el principio de igualdad en materia tributaria incorporaremos la expresión "(IGU)".

Por tanto,

$$
U A=\{D C(I G U)\}
$$

\subsection{Universo de soluciones: US}

Procede determinar el universo de soluciones (US). El universo de soluciones se puede definir como el "conjunto de soluciones normativas del sistema normativo analizado" 26 .

Existen cuatro operadores deónticos que nos permiten calificar una acción. Ellos son: obligatorio, prohibido, facultativo y permitido; siguiendo con la tradición, le asignaremos los siguientes símbolos $\boldsymbol{O}, \boldsymbol{P} \boldsymbol{b}, \boldsymbol{F}$ y $\boldsymbol{P}$, respectivamente.

Para nuestros efectos, se limitará la extensión del US a los operadores deónticos prohibido y permitido. Se usará el operador deóntico prohibido para aquellos casos en que el Estado esté impedido de exigir contribuir al sostenimiento de los gastos públicos en relación con el principio de igualdad en materia tributaria; se usará el operador deóntico prohibido para aquellos casos en que el Estado no esté impedido de exigir contribuir al sostenimiento de los gastos públicos en relación con el principio de igualdad en materia tributaria;

Por tanto, nuestro US contiene el siguiente elemento:

$$
U S=\{P h \mathrm{DC}(\mathrm{IGU}) \times \boldsymbol{P} \mathrm{DC}(\mathrm{IGU})\}
$$

\footnotetext{
${ }^{25}$ Martínez Zorrilla, D. (2010). Metodología y argumentación. Madrid: Marcial Pons, p. 286.

${ }^{26}$ Martínez Zorrilla, D. (2010). Metodología y argumentación. Madrid: Marcial Pons, p. 287.
} 


\subsubsection{Normas y respuestas del sistema normativo}

Procede representar formalmente las normas del sistema, esto es, enunciados que correlacionan casos con soluciones.

Para estos efectos es necesario considerar las distintas combinaciones que se pueden obtener con las propiedades relevantes establecidas anteriormente.

Del razonamiento de las SSTC que se ha analizado y en un esfuerzo interpretativo por obtener un sistema normativo ideal, es posible construir cinco normas para nuestro sistema normativo $S N_{\text {IGU }}$.

La primera norma puede expresarse así: si la desigualdad de trato ante la ley tributaria no se produce en un caso normal y, por tanto, el legislador racional no pudo haberlo previsto, entonces está permitido exigir contribuir al sostenimiento de los gastos públicos en relación con el principio de igualdad en materia tributaria. Se representará esta norma de la siguiente manera:

$$
N_{1}=\neg C N \rightarrow P \text { DC }(\mathrm{IGU})
$$

La segunda norma puede expresarse así: si la desigualdad de trato ante la ley tributaria se produce en un caso normal, pero no existe homogeneidad en los términos de comparación tratados desigualmente, entonces está permitido exigir contribuir al sostenimiento de los gastos públicos en relación el principio de igualdad en materia tributaria. Se representará esta norma de la siguiente manera:

$$
N_{2}=C N \cdot \neg H \rightarrow P \text { DC }(\mathrm{IGU})
$$

La tercera norma puede expresarse así: si la desigualdad de trato ante la ley tributaria se produce en un caso normal, existe homogeneidad en los términos de comparación tratados desigualmente, pero no existe una justificación objetiva y razonable que fundamente la desigualdad de trato ante la ley tributaria, entonces está prohibido exigir contribuir al sostenimiento de los gastos públicos en relación con el principio de igualdad en materia tributaria. Se representará esta norma de la siguiente manera:

$$
N_{3}=C N \cdot H \cdot \neg J \rightarrow P b D C(\mathrm{IGU})
$$

La cuarta norma puede expresarse así: si la desigualdad de trato ante la ley tributaria se produce en un caso normal, existe homogeneidad en los términos de comparación tratados desigualmente, existe una justificación objetiva y razonable que fundamente la desigualdad de trato ante la ley tributaria, pero no existe proporcionalidad entre los medios utilizados y la finalidad perseguida, entonces está prohibido exigir contribuir al sostenimiento de los gastos públicos en relación con el principio de igualdad en materia tributaria. Se representará esta norma de la siguiente manera:

$$
N_{4}=C N \cdot H \cdot J \cdot \neg P \rightarrow P h \mathrm{DC}(\mathrm{IGU})
$$


La quinta norma puede expresarse así: si la desigualdad de trato ante la ley tributaria se produce en un caso normal, existe homogeneidad en los términos de comparación tratados desigualmente, existe una justificación objetiva y razonable que fundamente la desigualdad de trato ante la ley tributaria y existe proporcionalidad entre los medios utilizados y la finalidad perseguida, entonces está permitido exigir contribuir al sostenimiento de los gastos públicos en relación con el principio de igualdad en materia tributaria. Se representará esta norma de la siguiente manera:

$$
N_{5}=C N \cdot H \cdot J \cdot P \rightarrow P \mathrm{DC}(\mathrm{IGU})
$$

Por lo tanto,

$$
S N_{I G U}=\left\{N_{1}, N_{2}, N_{3}, N_{4}, N_{5}\right\}
$$

Estamos en condiciones de establecer las consecuencias lógicas que nuestro $S N_{\text {IGU }}$ establece para cada uno de los casos del UC; en otros términos, se determinarán las respuestas del sistema normativo para cada uno de sus casos genéricos.

Se representarán las respuestas del sistema por medio de la matriz que se inserta en la página siguiente. Se utiliza el símbolo + para representar la concurrencia de una

\begin{tabular}{|c|c|c|c|c|c|c|c|c|c|}
\hline & \multicolumn{4}{|c|}{$U P$} & \multicolumn{5}{|c|}{$S N_{I G U}$} \\
\hline$U C$ & $H$ & $J$ & $P$ & $C N$ & $N_{1}$ & $\mathrm{~N}_{2}$ & $N_{3}$ & $N_{4}$ & $N_{5}$ \\
\hline 1 & + & + & + & + & & & & & $P$ DC(IGU) \\
\hline 2 & - & + & + & + & & $\boldsymbol{P}$ DC(IGU) & & & \\
\hline 3 & + & - & + & + & & & $P h \mathrm{DC}(\mathrm{IGU})$ & & \\
\hline 4 & - & - & + & + & & $P$ DC(IGU) & & & \\
\hline 5 & + & + & - & + & & & & $P h \mathrm{DC}(\mathrm{IGU})$ & \\
\hline 6 & - & + & - & + & & $P$ DC(IGU) & & & \\
\hline 7 & + & - & - & + & & & $P h \mathrm{DC}(\mathrm{IGU})$ & & \\
\hline 8 & - & - & - & + & & $\boldsymbol{P}$ DC(IGU) & & & \\
\hline 9 & + & + & + & - & $\boldsymbol{P}$ DC(IGU) & & & & \\
\hline 10 & - & + & + & - & $P$ DC(IGU) & & & & \\
\hline 11 & + & - & + & - & $\boldsymbol{P}$ DC(IGU) & & & & \\
\hline 12 & - & - & + & - & $\boldsymbol{P}$ DC(IGU) & & & & \\
\hline 13 & + & + & - & - & $P$ DC(IGU) & & & & \\
\hline 14 & - & + & - & - & $P$ DC(IGU) & & & & \\
\hline 15 & + & - & - & - & $\boldsymbol{P}$ DC(IGU) & & & & \\
\hline 16 & - & - & - & - & $\boldsymbol{P}$ DC(IGU) & & & & \\
\hline
\end{tabular}
propiedad relevante y el símbolo - para representar su ausencia.

Observando la matriz podemos concluir que el sistema normativo construido es consistente, pleno e independiente. 
a) El sistema es consistente porque regula de manera no contradictoria la totalidad de los casos genéricos que lo componen.

b) El sistema es pleno porque ofrece una respuesta (solución normativa) para todos y cada uno de los casos genéricos que lo componen.

c) El sistema es independiente porque sus normas regulan los casos genéricos que lo componen de manera no redundante.

\section{CONCLUSIÓN}

Al comienzo de este trabajo nos planteamos el propósito de analizar jurisprudencia de Derecho Comparado para establecer diferentes criterios que permitan establecer cuándo una desigualdad de trato en materia tributaria puede ser considerada arbitraria y, por tanto, una vulneración de este principio.

La concretización del principio de igualdad en materia tributaria por parte del Tribunal Constitucional español permite concluir que, partiendo del supuesto de que exista una desigualdad de trato ante la ley tributaria, las propiedades relevantes son las cuatro siguientes: a) que exista homogeneidad entre los términos de comparación tratados desigualmente ante la ley tributaria; b) que exista una finalidad que justifique la desigualdad de trato ante la ley tributaria; c) que exista proporcionalidad entre los medios utilizados y la finalidad perseguida; d) que se trate de un caso normal que pudiese haber previsto un legislador racional.

Se prohíbe exigir contribuir al sostenimiento de los gastos públicos si, y solo si, se configuran los siguientes tres casos genéricos: primer caso, concurren las propiedades relevantes signadas con las letras a), c) y d), sin que concurra la propiedad relevante signada con la letra b); segundo caso, concurren las propiedades relevantes signadas con las letras a), b) y d), sin que concurra la propiedad relevante signada con la letra c); tercer caso, concurren las propiedades relevantes signadas con las letras a) y d), sin que concurran las propiedades relevantes signadas con las letras b) y c).

Habiendo determinado los resultados del análisis de la jurisprudencia constitucional española para la concretización del principio de igualdad en materia tributaria es posible constatar que el modelo de análisis lógico de sistemas normativos desarrollado por Alchourrón y Bulygin permite realizar una reconstrucción válida, racional y sistematizada de los criterios jurisprudenciales.

Este trabajo se realizó con la convicción de que los resultados obtenidos tendrán valor no solo como mera sistematización de acontecimientos pasados en el ordenamiento jurídico español, sino como criterios para resolver casos futuros del ordenamiento jurídico chileno. Si bien los resultados de un sistema normativo extranjero no resultan vinculantes al sistema normativo chileno, considerando la regulación del principio de igualdad en materia tributaria es posible establecer que existen semejanzas relevantes entre ambos sistemas normativos y, por tanto, en la medida que se mantengan las propiedades relevantes, los casos específicos chilenos futuros podrán subsumirse en alguno de los casos genéricos determinados en este trabajo y resolverse teniendo como guía la solución normativa española. 


\section{BiBLIOGRAFÍA}

Alchourrón, C., \& Bulygin, E. (1974. Trabajo original publicado en 1971). Introducción a la metodología de las ciencias jurídicas y sociales. (C. Alchourrón, \& E. Bulygin, Trads.) Buenos Aires: Astrea.

Alchourrón, C., \& Bulygin, E. (1991). Análisis lógico y Derecho. Madrid: Centro de Estudios Constitucionales.

Guastini, R. (1999. Trabajo original publicado en 1996). Los principios en el derecho positivo. En R. Guastini, Distinguiendo (J. Ferrer, Trad., págs. 147-178). Barcelona: Gedisa.

Guastini, R. (1999. Trabajo original publicado en 1996). Norma: una noción controvertida. En R. Guastini, Distinguiendo. Estudios de teoría y metateoría del derecho (J. Ferrer, Trad.). Barcelona: Gedisa.

Martínez Zorrilla, D. (2007). Conflictos constitucionales, ponderación e indeterminación normativa. Madrid: Marcial Pons.

Martínez Zorrilla, D. (2010). Metodología y argumentación. Madrid: Marcial Pons.

Mendonca, D. (2000). Las claves del derecho. Barcelona: Gedisa.

Mendonca, D. (2003). Los derechos en juego. Conflicto y balance de derechos. Madrid: Tecnos.

Mendonca, D. (2011). Compendio de una teoría analítica del derecho. Alchourrón y Bulygin en sus textos. Madrid; Barcelona; Buenos Aires: Marcial Pons.

Mendonca, D., \& Guibourg, R. (2004). La odisea constitucional. Madrid; Barcelona: Marcial Pons.

Moreso, J. J. (2002). “Guastini sobre la ponderación” en Isonomía, 17: págs. 227-245.

Moreso, J. J. (2003). Conflictos entre principios constitucionales. En M. Carbonell (ed.), Neoconstitucionalismos (págs. 99-121). Madrid: Trotta.

Moreso, J. J. (2006). Lógica, argumentación e interpretación en el derecho. Barcelona: UOC.

Moreso, J. J. (2009). La Constitución: modelo para armar. Madrid: Marcial Pons.

Moreso, J. J., \& Vilajosana, J. M. (2004). Introducción a la Teoría del Derecho. Barcelona: Marcial Pons.

Vilajosana, J. M. (2007). Identificación y justificación del derecho. Barcelona: Marcial Pons. 
